\title{
Application of Analytic Hierarchy Process (AHP) on Constrained Pairings Selection from Flight Schedule
}

\author{
Mohamad Yusak Anshori ${ }^{1}$, Teguh Herlambang ${ }^{2}$, Dinita Rahmalia ${ }^{3}$ \\ Email: yusak.anshori@unusa.ac.id, teguh@unusa.ac.id \\ Management Department, University of Nahdlatul Ulama Surabaya ${ }^{1}$, Information System \\ Department, University of Nahdlatul Ulama Surabaya ${ }^{2}$, Mathematics Department, University \\ of Islam Darul Ulum Lamongan ${ }^{3}$
}

\begin{abstract}
Indonesia is a large country so that the demands of flight service are very high. Because the demands of flight service, flight industry should minimize operational cost such as crew cost. Crew cost depends on pairings from flight schedule. Optimization model of this problem is selecting optimal pairings covering all flight numbers. In this research, optimal pairing selection will be applied by Analytic Hierarchy Process (AHP). AHP requires the decision maker to provide judgements about the relative importance of each criteria and then specify a preference for each decision alternative using each criteria. By using AHP, we can determine the overall priority for each decision alternative.
\end{abstract}

Keywords: Analytic Hierarchy Process, Optimal Pairing Selection, Binary Programming, Greedy Algorithm

\section{Introduction}

Nowadays, linear programming as one of optimization problems have been applied such as: transportation problem minimizing cost (Rahmalia and Herlambang, 2018), production planning optimization (Rahmalia and Rohmah, 2018), pairings selection problem (Rahmalia et al, 2013). Generally, in the optimization problem, there are some constraints which should be satisfied. There are some techniques for solving constrained optimization such as simplex method (Taha, 2007; Hillier and Lieberman, 2001), heuristic methods for approaching (Rahmalia, 2017), giving the penalty score if the solution does not satisfy the constraint (Rahmalia, 2018), goal programming for multiobjective optimization (Rahmalia et al, 2018). This research will develop pairings selection problem from flight schedule of flight company in Indonesia.

Indonesia is a large country so that the demands of flight service are very high. Because the demands of flight service, flight industry should minimize operational cost such as crew cost. Crew cost depends on pairings from flight schedule (Rahmalia et al, 2013). Optimization model of this problem is selecting optimal pairings covering all flight numbers. The method used in order that all flight numbers are covered at least one pairing is greedy algorithm. Because the solutions of this problem are binary then the mathematical model is binary programming. 
In this research, optimal pairing selection will be applied by Analytic Hierarchy Process (AHP). However, before AHP is applied, we generate a set of possible pairing of each flight number. After the set of possible pairings are generated, they will be determined a set of selected pairings subject to all flight number are covered at least one pairing. Then, we make some sets of set of selected pairings as decision alternatives by greedy algorithm. AHP requires the decision maker to provide judgements about the relative importance of each criteria and then specify a preference for each decision alternative using each criteria. By using AHP, we can determine the overall priority for each decision alternative (Anderson et al, 2012).

\section{Method}

\subsection{Pairing and Deadhead}

Pairing is the sequence of flights drived by a set of crews started from the airport in first flight until to the same airport in last flight. Each pairing is driven by a set of crews. Therefore the crews depart and arrive in the same airport (homebase) in their duty.

The method for constructing pairing is using possibility matrix $A^{n}, n=2,3,4,5,6$. Possibility matrix $A^{n}$ keeps pairing consisting of $n$ flight numbers so that each column of possibility matrix $A^{n}$ has $n$ elements with score equals 1 . Pairing illustration can be seen on Figure 1. Pairing $A^{n}$ consists of $n$ flight numbers (Rahmalia et al, 2013).

\begin{tabular}{|c|c|c|c|c|c|c|c|c|}
\hline $\begin{array}{c}\text { Pre } \\
\text { Journey } \\
\text { (90 mnt) }\end{array}$ & $\begin{array}{l}\text { Flight } 1 \\
(\mathrm{~A} \rightarrow \mathrm{B})\end{array}$ & $\begin{array}{c}\text { Transit } \\
\text { Time } \\
\text { (TT) }\end{array}$ & $\begin{array}{l}\text { Flight } 2 \\
(B \rightarrow C)\end{array}$ & $\begin{array}{l}\text { Transit } \\
\text { Time } \\
\text { (Tा) }\end{array}$ & $\begin{array}{l}\text { Flight } 3 \\
(C \rightarrow D)\end{array}$ & $\begin{array}{c}\text { Transit } \\
\text { Time } \\
\text { (TT) }\end{array}$ & $\begin{array}{l}\text { Flight } 4 \\
(D \rightarrow A)\end{array}$ & $\begin{array}{c}\text { Post } \\
\text { Journey } \\
\text { (90 mnt) }\end{array}$ \\
\hline
\end{tabular}

Figure. 1 Pairing Illustration

In the pairing selection, there are some cases the flight numbers are deadhead. Deadhead is the case in which there are same flight numbers in the different pairing. This problem causes a set of crews is transfered to destination airport with other flight in different pairing.

\subsection{Mathematical Model of Optimal Pairing Selection}

Optimal pairing selection can be done by generating a set of possible pairing of each flight number. After the set of possible pairings are generated, they will be determined a set of selected pairings subject to all flight number are covered at least one pairing.

Mathematical model of optimal pairing selection is binary programming with the model as follows:

$$
\begin{gathered}
\sum_{k=1}^{N_{P}} a_{i k} x_{k} \geq 1, \quad i=1,2, \ldots, N_{F} \\
x_{k} \in\{0,1\}, k=1,2, \ldots, N_{P}
\end{gathered}
$$


Variables used are :

$N_{P}$ : The number of possible pairing

$N_{F}$ : Total flight numbers

$$
a_{i k}=\left\{\begin{array}{rr}
1, & \text { if flight number } \mathrm{i} \text { is covered in pairing } \mathrm{k} \\
0, & \text { otherwise }
\end{array}\right.
$$

with a set of selected pairings as decision alternatives are :

$$
x_{k}=\left\{\begin{array}{rr}
1, & \text { if pairing } \mathrm{k} \text { is selected } \\
0, & \text { otherwise }
\end{array}\right.
$$

\subsection{Generating the Set of Selected Pairings}

Before using AHP, we need to initialize a set of $M$ sets of selected pairings as decision alternatives by greedy algorithm. Greedy algorithm is applied because it can cover all flight numbers at least one pairing based on equation (1). Because the solutions of this problem are binary then the mathematical model is binary programming. The algorithm to initialize a set of $M$ sets of selected pairings as decision alternatives is as follows:

for $j=1: M$

1. Suppose $U$ is the set of uncovered flight number, $S_{i}, i=1,2, \ldots, N_{F}$ is the set of a selected pairing, $w_{i}, i=1,2, \ldots, N_{F}$ is the number of pairing covering flight number $i$, and $x_{k}=0, k=1,2, \ldots, N_{P}$ is the decision variable solution i.e. selected pairings.

2. Set $U=F, S_{i}=\{\}, w_{i}=0$ for every $i=1,2, \ldots, N_{F}, x_{k}=0$ for every $k=1,2, \ldots, N_{P}$

For $i=1: N_{F}$

If $\left(w_{i}=0\right)$

a. Determine $P_{i}$ : the set of pairings covering flight number $i$

b. Choose pairing $q \in P_{i}$ randomly

c. Determine $F_{q}$ : the set of flight numbers covered by pairing $q \in P_{i}$

d. Update $S_{i} \leftarrow S_{i} \cup q, w_{i} \leftarrow w_{i}+1$ for $i \in F_{q}$

e. Update $U \leftarrow U-F_{q}, x_{q}=1$

end

end

end

\subsection{Analytic Hierarchy Process (AHP)}

Analytic hierarchy process (AHP) was developed by Thomas L. Saaty to solve multicriteria decision problems. AHP requires the decision maker to provide judgements 
about the relative importance of each criteria and then specify a preference for each decision alternative using each criteria. The output of AHP is a prioritized ranking of the decision alternatives based on the overall preferences expressed by the decision maker.

The first step in AHP is developing a graphical representation of the problem such as the overall goal, the criteria, and the decision alternatives. Graphical representation of optimal pairing selection can be seen on Figure. 2. The goal is selecting the best set of selected pairings from $M$ decision alternatives. In the set of selected pairings, there are some criterias such as deadhead, pairing $\mathrm{A}^{2}$, pairing $\mathrm{A}^{3}$, pairing $\mathrm{A}^{4}$, pairing $\mathrm{A}^{5}$, and pairing $\mathrm{A}^{6}$ to be analyzed.

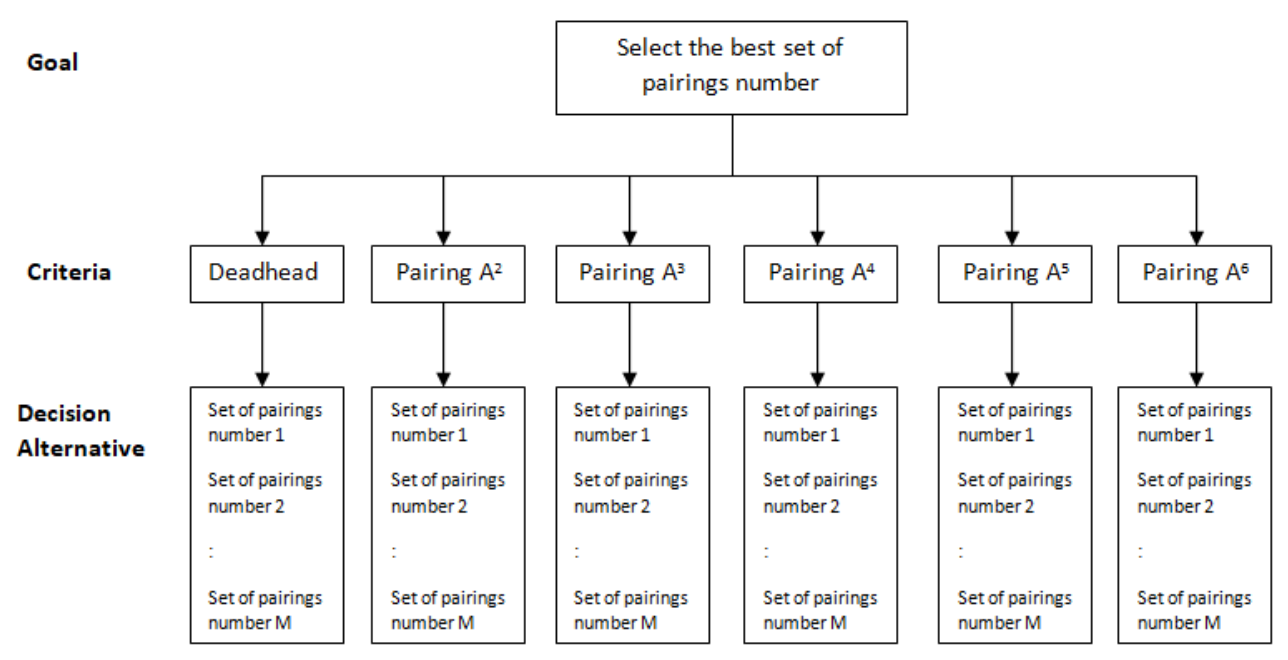

Figure. 2 Graphical Representation of Optimal Pairing Selection

Table 1 shows comparison scale for the importance rate which will be used in AHP.

Table. 1 Comparison Scale for the Importance Rate

\begin{tabular}{lc}
\hline \multicolumn{1}{c}{ Verbal Judgement } & Numerical Rating $c$ \\
\hline Very Important & 6 \\
& 5 \\
Important & 4 \\
& 3 \\
Sufficient Important & 2 \\
Equally Important & 1 \\
\hline
\end{tabular}

The steps of AHP to determine the overall priority of each decision alternative are as follows:

1. Construct the pairwise comparison matrix with elements $p_{i j}$ are : 


$$
\begin{gathered}
p_{i j}=1 \text { if } i=j \\
p_{i j}= \begin{cases}c & \text { if criteria i is more important than criteria } \mathrm{j} \\
\frac{1}{c} & \text { if criteria } \mathrm{j} \text { is more important than criteria } \mathrm{i}\end{cases}
\end{gathered}
$$

2. Sum the values in each column of the pairwise comparison matrix.

3. Divide each element in the pairwise comparison matrix by its column total. The resulting matrix is called as the normalized pairwise comparison matrix.

4. Compute the average of the elements in each row of the normalized pairwise comparison matrix. These averages are the priorities for the criteria. High priorities indicate high importance.

5. For each criteria, do steps 1-4 to compare each decision alternative.

6. Determine the overall priority for each decision alternative.

$$
Q_{j}=\sum_{i} z_{i} r_{i j}
$$

$z_{i}$ : the weight for criteria $i$

$r_{i j}$ : the rating for criteria $i$ and decision alternative $j$

\section{Result and discussion.}

Data used in this research are from flight schedule of flight company in Indonesia by Boeing B738 airline on February 3, 2012. First, we generate a set of possible pairing of each flight number. After the set of possible pairings are generated, they will be determined a set of selected pairings subject to all flight number are covered at least one pairing. Then, we need to initialize a set of 30 sets of selected pairings as decision alternatives.

From the sets of selected pairings, we can design pairwise comparison matrix to compare deadhead, pairing $\mathrm{A}^{2}$, pairing $\mathrm{A}^{3}$, pairing $\mathrm{A}^{4}$, pairing $\mathrm{A}^{5}$ and pairing $\mathrm{A}^{6}$ as in Table 2.

Table. 2 Pairwise Comparison Matrix

\begin{tabular}{lllllll}
\hline & Deadhead & Pairing $A^{2}$ & Pairing $A^{3}$ & Pairing $A^{4}$ & Pairing $A^{5}$ & Pairing $A^{6}$ \\
\hline Deadhead & 1 & 0.500 & 0.333 & 0.250 & 0.200 & 0.167 \\
Pairing A & 2 & 1 & 0.333 & 0.250 & 0.200 & 0.167 \\
Pairing A & 3 & 3 & 1 & 0.250 & 0.200 & 0.167 \\
Pairing A & 4 & 4 & 4 & 1 & 0.200 & 0.167 \\
Pairing A $^{5}$ & 5 & 5 & 5 & 5 & 1 & 0.167 \\
Pairing A & 6 & 6 & 6 & 6 & 6 & 1 \\
\hline
\end{tabular}

After using AHP, the overall priority of 30 decision alternatives can be seen in Figure 3. 


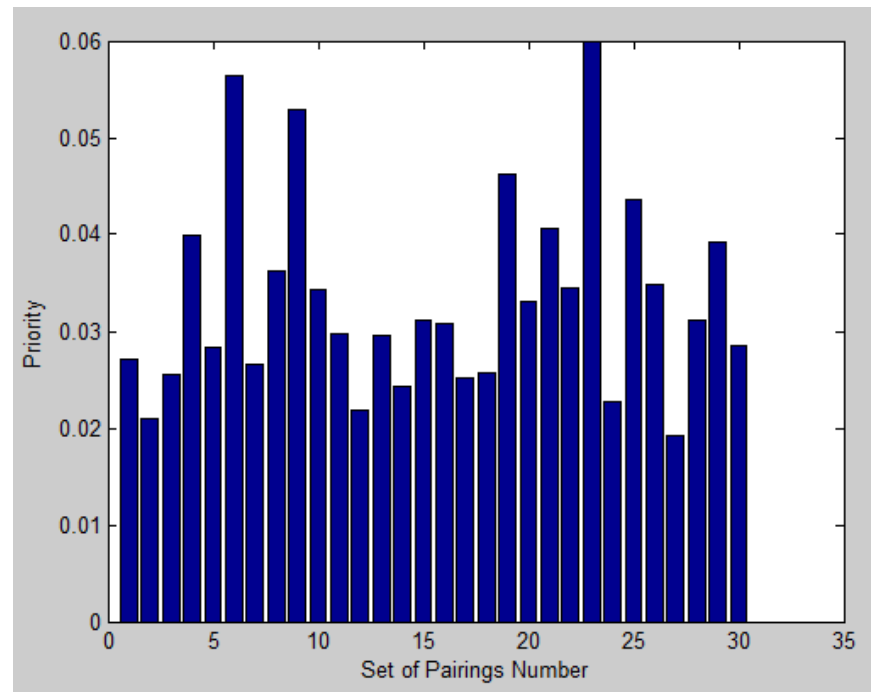

Figure. 3 Graph of priority of each decision alternative

From the graph, the five best decision alternatives of a set of selected pairings with their priority are shown in Table 3.

Table. 3 Five Best Decision Altervatives

\begin{tabular}{cc}
\hline Number & Priority \\
\hline 23 & 0.0599 \\
6 & 0.0565 \\
9 & 0.0528 \\
19 & 0.0463 \\
25 & 0.0436 \\
\hline
\end{tabular}

From the graph, five worst decision alternatives of a set of selected pairings with their priority are shown in Table 4.

Table. 4 Five Worst Decision Alternatives

\begin{tabular}{cc}
\hline Number & Priority \\
\hline 14 & 0.0243 \\
24 & 0.0227 \\
12 & 0.0219 \\
2 & 0.0211 \\
27 & 0.0191 \\
\hline
\end{tabular}




\section{Conclusion.}

There are some steps in optimal pairing selection. We generate a set of possible pairing of each flight number. After the set of possible pairings are generated, they will be determined a set of selected pairings subject to all flight number are covered at least one pairing. Then, we need to initialize a set of sets of selected pairings as decision alternatives. From the sets of selected pairings, we can design pairwise comparison matrix. By using AHP, we can determine the overall priority for each decision alternative.

\section{References}

[1] F.S Hillier, and G.J Lieberman, Introduction to Operations Research, New York, USA : Mc Graw Hill, 2001

[2] H.A Taha, Operations Research : An Introduction. New Jersey, USA : Prentice Hall, 2007

[3] D.R Anderson, D.J Sweeney and T.A Williams, An Introduction to Management Science: Quantitative Approaches to Decision Making, USA : South-Western Cengange Learning, 2012

[4] D Rahmalia, Particle Swarm Optimization-Genetic Algorithm (PSOGA) on Linear Transportation Problem, AIP Conference Proceeding, pp. (020030)1-12, 2017

[5] D Rahmalia and T Herlambang, Optimisasi Masalah Transportasi Distribusi Semen Menggunakan Algoritma Artificial Bee Colony, Multitek Indonesia, 11(2), 2018

[6] D Rahmalia and A.M Rohmah, Optimisasi Perencanaan Produksi Pupuk Menggunakan Firefly Algorithm, Jurnal Matematika MANTIK, 4 (1), 2018

[7] D Rahmalia, Teknik Penalti pada Optimisasi Berkendala Menggunakan Particle Swarm Optimization, JMPM : Jurnal Matematika dan Pendidikan Matematika, 3 (1) 44-52, 2018

[8] D Rahmalia, T.E Saputro, and T Herlambang, Goal Programming on Production Planning Using Ant Colony Optimization-Genetic Algorithm (ACOGA), Proceeding $5^{\text {th }}$ International Conference on Research, Implementation, and Education of Mathematics and Science, 2018

[9] D Rahmalia and T Herlambang, Application Kohonen Network and Fuzzy C Means for Clustering Airports Based on Frequency of Flight', Kinetik: Game Technology, Information System, Computer Network, Computing, 3(3), 229-236, 2018

[10] D Rahmalia, R. Hadianti and K Novianingsih, Optimisasi Crew Pairing dengan Memodifikasi Jadwal Penerbangan. Tesis Magister Matematika ITB, 2013. 